\title{
New WC-Cu thermal barriers for fusion applications: High temperature mechanical behaviour
}

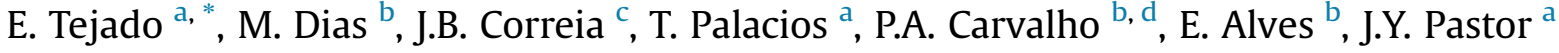 \\ a Departamento de Ciencia de Materiales-CIME, Universidad Politécnica de Madrid, c/ Profesor Aranguren 3, E28040, Madrid, Spain \\ ${ }^{\mathrm{b}}$ Instituto de Plasmas e Fusão Nuclear, Instituto Superior Técnico, Universidade de Lisboa, Av. Rovisco Pais, 1049-001, Lisboa, Portugal \\ ${ }^{c}$ LNEG, Laboratório Nacional de Energia e Geologia, Estrada Do Paço Do Lumiar, 1649-038, Lisboa, Portugal \\ d CEFEMA, Instituto Superior Técnico, Universidade de Lisboa, Av. Rovisco Pais, 1049-001, Lisboa, Portugal
}

\section{A R T I C L E I N F O}

\section{Article history:}

Received 13 February 2017

Received in revised form

30 October 2017

Accepted 30 October 2017

Available online 3 November 2017

\section{Keywords:}

WC-Cu cermet

Thermal barrier

Mechanical properties

Thermal properties

\begin{abstract}
A B S T R A C T
The combination of tungsten carbide and copper as a thermal barrier could effectively reduce the thermal mismatch between tungsten and copper alloy, which are proposed as base armour and heat sink, respectively, in the divertor of future fusion reactors. Furthermore, since the optimum operating temperature windows for these divertor materials do not overlap, a compatible thermal barrier interlayer between them is required to guarantee a smooth thermal transition, which in addition may mitigate radiation damage.

The aim of this work is to study the thermo-mechanical properties of WC-Cu cermets fabricated by hot pressing. Focus is placed on the temperature effect and composition dependence, as the volume fraction of copper varies from 25 to 50 and $75 \mathrm{vol} \%$. To explore this behaviour, fracture experiments are performed within a temperature range from room temperature to $800^{\circ} \mathrm{C}$ under vacuum. In addition, elastic modulus and thermal expansion coefficient are estimated from these tests.

Results reveal a strong dependence of the performance on temperature and on the volume fraction of copper and, surprisingly, a slight percent of $\mathrm{Cu}(25 \mathrm{vol} \%)$ can effectively reduce the large difference in thermal expansion between tungsten and copper alloy, which is a critical point for in service applications. The thermal performance of these materials, together with their mechanical properties could indeed reduce the heat transfer from the PFM to the underlying element while supporting the high thermal stresses of the joint. Thus, the presence of these cermets could allow the reactor to operate above the ductile to brittle transition temperature of tungsten, without compromising the underlying materials.
\end{abstract}

(c) 2017 Elsevier B.V. All rights reserved.

\section{Introduction}

Carbide cermets have historically been developed to provide protection against corrosion and erosion for applications in oil and gas industry, but also against heat as Thermal Barrier (TBs) to control the heat flow and retard rapid chilling. For instance, TBs have the capability to improve the durability of engines by reducing the surface temperature of the underlying components [1]. This aspect could be of great importance for future fusion power plants, such as DEMO, since the final design of ITER is already defined, where the adequate control of the heat exhaust is presently being

\footnotetext{
* Corresponding author.

E-mail address: elena.tejado@upm.es (E. Tejado).
}

explored [2]. One of the proposed design models for the DEMO divertor is based on a monoblock structure consisting of tungsten armour as plasma facing material and $\mathrm{CuCrZr}$ alloy as heat sink [3].

Tungsten is considered the prime candidate as plasma facing material due to its high melting point, high sputtering threshold and low tritium inventory [4-7]. Owing to the rather high ductilebrittle transition temperature (DBTT) of $\mathrm{W}$ (around $300{ }^{\circ} \mathrm{C}$ ) [8], operation at high temperatures is desirable both for thermal efficiency and better performance of the $\mathrm{W}$ tiles at the first wall of the reactor. On the other hand, $\mathrm{CuCrZr}$ alloy has been selected as heat sink material due to its high conductivity and high strength [9] and it will be used to remove heat from the plasma facing components in the first wall. However, the service temperature of this material is relatively low $\left(180{ }^{\circ} \mathrm{C}<\mathrm{T}<350^{\circ} \mathrm{C}\right)$ [10], as softening and creep are observed at temperatures around $300-350{ }^{\circ} \mathrm{C}$, besides, it 